\title{
Investigation of Filtering and Drying Process of Microalgae Pilot Plant
}

\author{
Muhammad Rohaizad Shari ${ }^{1}$, Fathul Hakim Zulkifli ${ }^{2}$, Norshuhaila Muhamed Sunar ${ }^{3}$ \\ ${ }^{1}$ Malaysia Steel Works, Lot 13039, Jalan Waja, Bukit Raja Industrial Estate, 41050 Klang, Selangor, Malaysia, \\ muhdrohaizad07@gmail.com \\ ${ }^{2}$ Department of Mechanical Engineering Technology, Faculty of Engineering Technology, Universiti Tun Hussein \\ Onn Malaysia, 84600 Muar, Malaysia, fathul@uthm.edu.my \\ ${ }^{3}$ Deparment of Civil Engineering Technology, Faculty of Engineering Technology, Universiti Tun Hussein Onn \\ Malaysia, 84600 Muar, Malaysia, shuhaila@uthm.edu.my
}

\begin{abstract}
The increasing need for sustainable energy calls for the development of renewable and cost-effective alternative sources to reduce the use of fossil fuels. Biofuel is one of the substituted alternatives that are now well-recognised as a result of the increasing awareness of green environment and pollution. This study intended to produce dry biomass via a microalgae pilot plant. Previous research had produced the microalgae pilot plants, which consisted of cultivation, filtering, and drying process. However, the filtering process and drying process needed further investigation to obtain the optimum output. Two types of filters: (a) membrane filter was tested for the filtering process. The drying temperature was examined between $50^{\circ} \mathrm{C}$ and $80^{\circ} \mathrm{C}$. Results showed that the membrane filter produced high filtration rates with $53 \%$ of efficiency compared to the (b) paper filter, with 39\% of efficiency. The optimum drying temperature was observed at $70^{\circ} \mathrm{C}$, which produced the most effective dry microalgae.
\end{abstract}

Key words: Botrycoccussp, Drying Process, Dry Biomass, Filtering Process, Microalgae

\section{INTRODUCTION}

The world has been confronted with an energy crisis due to the depletion of finite resources of fossil fuel. Continued use of petroleum-based fuels is now widely recognised as unsustainable because of depletion. Primitively, energy production is sourced from petroleum, natural gas, coal, and fuel. In parallel to the massive need for energy, these non-renewable energies are depleting, thus the continuity of energy production is at risk for the future. Biofuel is one of the effective alternatives to substitute the usage of fossil fuels and can directly preserve non-renewable energy in the long run.

Based on the motivation of this issue, previous works had developed the microalgae pilot plant [1]. The microalgae pilot plant was developed to produce dry microalgae. Dry microalgae could not be extracted to produce biodiesel. There were a few consecutive processes in the pilot plant that involved the cultivation of microalgae flocculation, filtering, and drying. Dry microalgae are the raw material forbiofuel. Therefore, this study focused on the area of both the filtering and drying processes.

Previous works had not analysed the temperature for drying and filtering processes thoroughly. The present study examined the efficiency between two types of filters, the filter paper, and membrane filter. Additionally, this study investigated a suitable temperature for the drying process to produce dry microalgae. This research used the microalgae species such as the is Botryococcussp, which are collected from the tropical rainforest of South of Peninsular Malaysia. The harvested microalgae were dried at a temperature of $50^{\circ} \mathrm{C}$ to $80^{\circ} \mathrm{C}$.

\subsection{Microalgae as a source of biodiesel}

Microalgae are potentially used to produce biodiesel as a result of a similar oil and conventional biodiesel sources such as vegetable oil and animal fats [2]. Additionally, the oil content from microalgae is much higher and has an excellent growth rate compared to conventional oil crops, vegetables, oil, and animal fats as shown in Table 1 [3], [4].

However, there are a lot of species of microalgae. The species has a different level of lipid content as a result of the metabolite characteristic and strain. For example, Botryococcus sp. can produce up to $80 \%$ of lipid content compared to other species like Schizochytriumsp (50\%-77\%), Spirulina Maxima (6\%-7\%), and Nannochloropsis sp. (31\%-68\%) [5], [6]. It shows that Botryococcussp is one of the best microalgae to produce biodiesel because of its high concentration of lipid content in the organisms.

Table 1: Comparison of some sources of biodiesel [7]

\begin{tabular}{cc}
\hline Crop & Oil yield $\left(\mathrm{L} \cdot \mathrm{ha}^{-1}\right)$ \\
\hline Corn & 172 \\
Soybean & 446 \\
Canola & 1,190 \\
Jatropha & 1,892 \\
Coconut & 2,689 \\
Oil palm & 5,950 \\
Microalgae (70\% oil in biomass) & 136,900 \\
Microalgae (30\% oil in biomass) & 58,700 \\
\hline
\end{tabular}




\subsection{Harvesting of microalgae}

After the cultivation of microalgae, the microalgae were collected and harvested to get a dry microalgae powder [8]. The harvesting process consisted of flocculation, filtering, and drying the microalgae paste.

\subsection{Filtration process by using filter paper}

Filtration separates suspended solids from liquids and allows the latter to pass through the pore of the substance, called a filter. Filter paper has high porosities which allow it to absorb fine substances from large ones and separate them. Figure 1 shows the diagram of the filter paper to separate substances. Filter paper has different properties and varies for different applications.

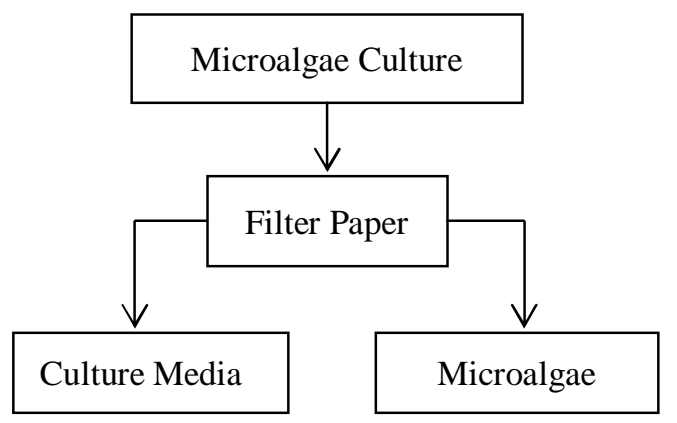

Figure 1: Diagram of filtration process

This process of filtration involved the microalgae culture, which was poured on the filter paper. The microalgae culture was the final product of the flocculation and contained cultivated microalgae and culture media, which served as a medium for the growth of microalgae. Hence, this research filtered and separated the culture media and the microalgae. This type of algae harvesting method was employed to retain the algae bio-mass while allowing the liquid to pass through [9].

\subsection{Drying process of microalgae}

The drying process comprised of the final stage of harvesting. This process was done after filtering the microalgae solution. Generally, drying removes moisture contained in the wet material via physical and chemical means [10]. After filtering, the microalgae are in a wet form and called the microalgae paste. Crude oil could not be extracted from microalgae paste because of its wet conditions. So, a drying process is required to convert the microalgae paste in dry form.

The drying process in biodiesel production is a highly energy-intensive process and becomes one of the biggest constraints in the utilisation of microalgae. Dry microalgae require approximately $85 \%$ of the total energy consumption in the microalgae biomass production process [10]. For example, thermal drying of microalgae consumes up to $3556 \mathrm{~kJ} / \mathrm{kg}-1$ of fossil fuel-based energy, which isnecessary to develop a drying process with very low energy consumption to make microalgae utilisation more competitive to generate power and other areas [11], [12]. The key issues need to be addressed to minimise the capital and operational costs, drying cost and extraction, and the development work to increase productivity by developing more efficient harvesting systems [13].

\subsection{Importance of drying process}

The drying process of microalgae has no single filtering and drying method that is suitable for all types of microalgae. The suitability of each method depends on the properties of the suspension of microalgae, the required process design, the quality of the end product, and the related capital, and production costs [14]. There is no all-purpose harvesting method that can treat all microalgae suspensions based on both cost and energy consumption [15]. Although harvesting resulted in a 50 to a 200 -fold concentration of microalgal biomass, the moisture in the harvested biomass slurry was still high enough to spoil the slurry within a few hours at room temperature [16]. A drying process is thus often needed to convert the slurry into a stable and storable form.

Post-microalgae filtering processes, the dry solid content of the biomass slurry was still low [14], [17]. Therefore, a drying process, such as solar drying, convective drying, spray drying, and freeze-drying, as needed, depending on the requirement of the final products [18].

\section{METHODOLOGY}

\subsection{Microalgae pilot plant}

The microalgae pilot plant in Figure 2 had been established and built by previous studies [1]. The pilot plant consisted of a cultivation tank, which could store up to 60 litres of fluids. The separation tank was designed to make flocculation of microalgae. After that, the microalgae were filtered to obtain microalgae paste. Then, the drying system was used to dry the microalgae. In this study, the analysis focused on the filtration and drying processes.

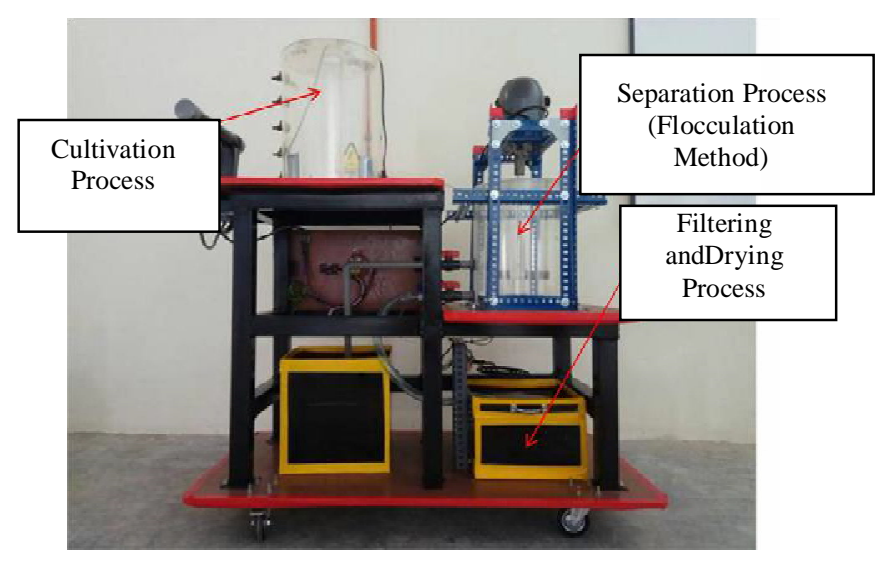

Figure 2: Microalgae pilot plant

\subsection{Cultivation of microalgae}

There were a few steps in the process of cultivation that were considered before the microalgae could be grown. First, the 
composition of chemicals in the solution of microalgae. These chemicals were present in the growth media. Table 2 shows that the media used Bold Basal Medium (BBM) for cultivation.

The main tank in Figure 3 is been cultured outdoor in the tank called photobioreactor (PBR). Fluid composition in the main tank is a mixture of a few types of fluids. Total microalgae in the culture tank are 40 litres and consist of 30 litres Bold Basal medium (BBM), 3 litres of wastewater, and 7 litres of distilled water. Wastewater was extracted from the food industry wastewater. The wastewater was chosen because it had a high concentration of essential nutrients needed by the microalgae. The wastewater medium was also considered more economical compared to synthetic media.

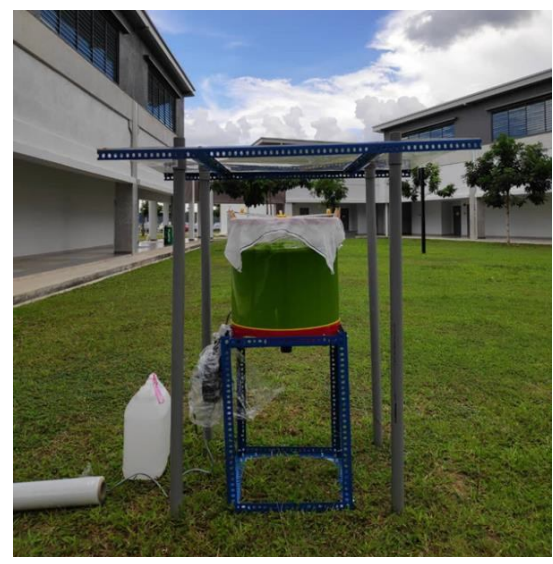

Figure 3: The main tank for cultivation process

The photobioreactors were maintained at the outdoor laboratory and the temporary structure was built to cover the microalgae culture. The roof's structure was from the thermoplastic sheet for a natural sunlight transmission. The local temperature varied from $24^{\circ} \mathrm{C}$ to $33^{\circ} \mathrm{C}$ throughout the day. Therefore, the selected location was suitable for the photosynthesis process of microalgae. Cultures were provided with low-pressure air pumps from the bottom of the photobioreactor. The air pumps maintained the exchange of $\mathrm{CO}_{2}$ and $\mathrm{O}_{2}$. On the other hand, the $\mathrm{pH}$ value was recorded between 7 and 10 during the cultivation process. The microalgae were grown for 14 days before the flocculation process.

\subsection{Composition of chemical for cultivation process}

Each component in Table 2 was dissolved into 800 millilitres of distilled water to make 10 bottles of different stock solutions. Every component in the stock solution was used to make 1 litre of Bold Basal Medium. About 10 millilitres and 1 millilitre were added for the rest of the stock solution between component 1 and 6 . Then, distilled water was used to fill the stock until it reached 1 litre. The 1 litre Bold Basal Medium was autoclaved at $121^{\circ} \mathrm{C}$ (15PSI for 15 minutes). After autoclaving the solution, it was left to cool at room temperature before microalgae seed was added. Then, microalgae grew for 14 days before the harvesting.
Table 2: Composition of Bold Basal Medium (BBM)

\begin{tabular}{ccc}
\hline No & Stock Solution & Per Litre of Distilled water $\left(\mathrm{H}_{2} \mathrm{O}\right)$ \\
\hline 1 & $\mathrm{NaNO}_{3}$ & $25.0 \mathrm{~g}$ \\
2 & $\mathrm{CaCl}_{2} \cdot 7 \mathrm{H}_{2} \mathrm{O}$ & $2.5 \mathrm{~g}$ \\
3 & $\mathrm{MgSO}_{4} \cdot 7 \mathrm{H}_{2} \mathrm{O}$ & $7.5 \mathrm{~g}$ \\
4 & $\mathrm{~K}_{2} \mathrm{HPO}_{4}$ & $7.5 \mathrm{~g}$ \\
5 & $\mathrm{KH}_{2} \mathrm{PO}_{4}$ & $17.5 \mathrm{~g}$ \\
6 & $\mathrm{NaCl}$ & $2.5 \mathrm{~g}$ \\
& $\mathrm{EDTA}$ & $50.0 \mathrm{~g}$ \\
7 & $\mathrm{KOH}$ & $31.0 \mathrm{~g}$ \\
& $\mathrm{FeSO}_{4} \cdot 7 \mathrm{H}_{2} \mathrm{O}$ & $4.89 \mathrm{~g}$ \\
8 & $\mathrm{H}_{2} \mathrm{SO}_{4}$ & $1.0 \mathrm{ml}$ \\
9 & $\mathrm{H}_{3} \mathrm{BO}_{4}$ & $11.42 \mathrm{~g}$ \\
& $\mathrm{Micronutrients}$ & $\mathrm{g} / \mathrm{L}$ \\
& $\mathrm{ZnSO}_{4} \cdot 7 \mathrm{H}_{2} \mathrm{O}$ & $8.82 \mathrm{~g}$ \\
10 & $\mathrm{MnCL}_{2} \cdot 4 \mathrm{H}_{2} \mathrm{O}$ & $1.44 \mathrm{~g}$ \\
& $\mathrm{MoO}_{3}$ & $0.71 \mathrm{~g}$ \\
& $\mathrm{CuSO}_{4} \cdot 5 \mathrm{H}_{2} \mathrm{O}$ & $1.57 \mathrm{~g}$ \\
& $\mathrm{Co}$ & $0.49 \mathrm{~g}$ \\
\hline
\end{tabular}

\subsection{Flocculation of microalgae}

Flocculation of the microalgae solution was done via an alum. Alum is a chemical compound, which consists of Aluminium Sulphate $\left(\mathrm{Al}_{2}\left(\mathrm{SO}_{4}\right)_{3} \cdot 18 \mathrm{H}_{2} \mathrm{O}\right)$. About 30 grams of Aluminium Sulphate was dissolved in 1 litre of distilled water. Next, about 400 millilitres of microalgae culture was used as a standard volume for each sample of the flocculation process. Then, the microalgae culture was added with 8 millilitres of alum dosage and gone through the flocculation process via the separation machine. The microalgae culture was then rapidly mixed for 3 minutes at $80 \mathrm{rpm}$ and slowly mixed at 20 minutes for $30 \mathrm{rpm}$. The settling period to obtain the sedimentation of the microalgae was a day before it was ready for the next process.

\subsection{Filter paper}

The filtration process was conducted based on two types of filters. Figure 4 shows the filter used in this study. Figure 4(a) is a Grade 4 qualitative filter paper with a pore size of 20-25 $\mu \mathrm{m}$, whereas Figure 4(b) is a membrane-type filter with pore sizes of $0.45 \mu \mathrm{m}$.

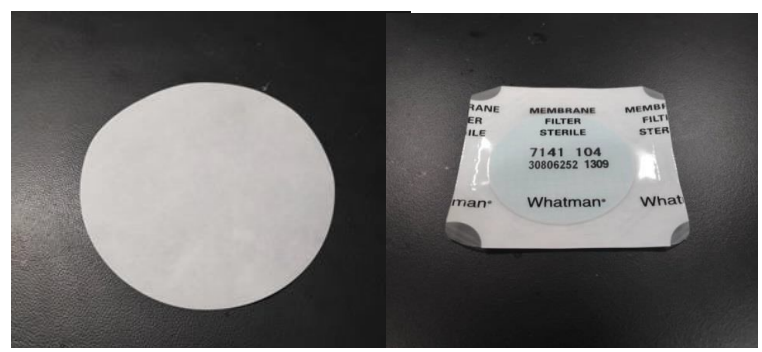

(a)

(b)

Figure 4: Filter use in the study (a) Filter Paper (b) membrane filter 


\subsection{Sample preparation}

This study employed 12 samples of microalgae solutions that were filtered via grade 4 qualitative filter paper. These 12 samples were divided equally based on the temperatures $50^{\circ} \mathrm{C}, 60^{\circ} \mathrm{C}, 70^{\circ} \mathrm{C}$, and $80^{\circ} \mathrm{C}$ during the drying process. Hence, every pre-set temperature had 3 samples for analysis. Meanwhile, the membrane filter used 3 samples. These 3 samples from the membrane filter were dried at a temperature of $60^{\circ} \mathrm{C}$. Figure 5 shows that every sample was filtered via a vacuum filter pump. The samples' filtration time and the weight of wet microalgae were recorded.

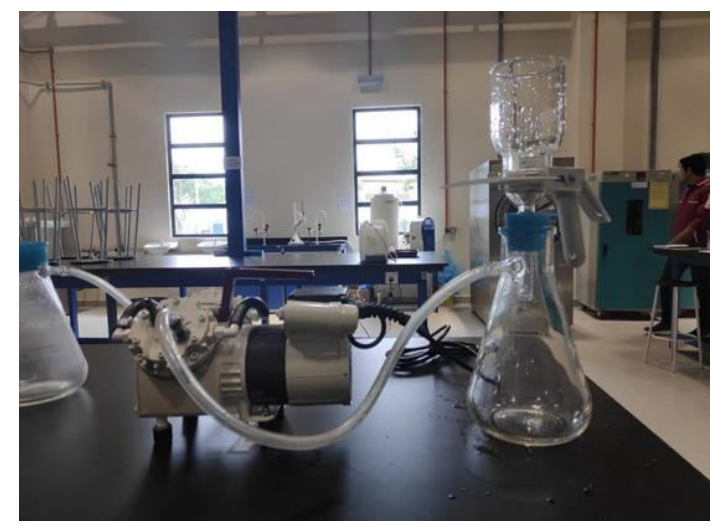

Figure 5: Vacuum filter pump

\subsection{Drying method}

Figure 6 shows the design and fabrication of the drying system. The wet microalgae paste was heated by a rod heater. Blower fan blew the heated wave to the wet microalgae paste to speed up the drying process.

The filtrate samples or microalgae paste at filter paper was placed in the drawer. Then, the road heater was heated to the pre-set temperature while the blower fan was on. The weight of the microalgae pastes pre- and post- drying process were recorded.

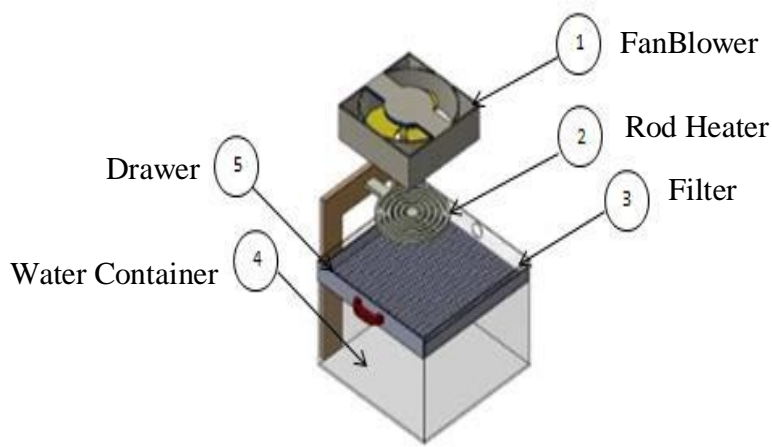

Figure 6:Drying System

\subsection{Extraction rate}

Equation 1 shows the equation to find the dry weight efficiency of microalgae. The weight before was the weight of microalgae before the drying process and the weight after was the weight of microalgae after the drying process.

$$
\text { Dry Weight Efficiency }=\frac{\text { Weight Before }- \text { Weight After }}{\text { Weight Before }} \times 100 \%
$$

\section{RESULTS AND DISCUSSIONS}

\subsection{Process of filtering}

Based on the samples prepared in Section 2.6, the filtering process was conducted in a lab-scale because the filtering system in the existing pilot plant was not suitable. The existing filtration system did not have a pressurized filter, which lengthens the filtration duration. The filtration of microalgae separated the water content in the sediment of microalgae culture. The microalgae culture was poured slowly to ensure the filtration did not take a longer time.

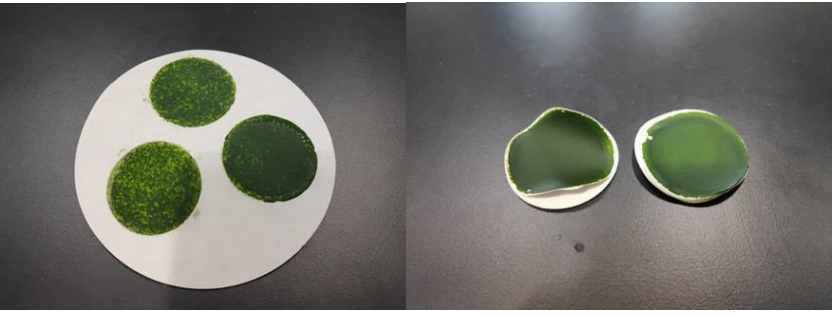

(a)

(b)

Figure 7:(a) Filtering using grade 4 filter paper (b) Filtering using membrane filter

Figure 7 shows the microalgae culture after being filtered by a vacuum filter pump via (a) filter paper and (b) membrane filter. On average, the filtration period for filter paper was 13.31 minutes whereas the membrane filter was 5.54 minutes. Based on the obtained data, the filtration via membrane filters produced a shorter period in comparison to filter papers.

\subsection{Process of drying}

Figure 8 shows the microalgae paste in the existing drying system of the microalgae pilot plant for the drying process. The drying process of microalgae was conducted in the existing system because the drying system was embedded in the pilot plant system. 


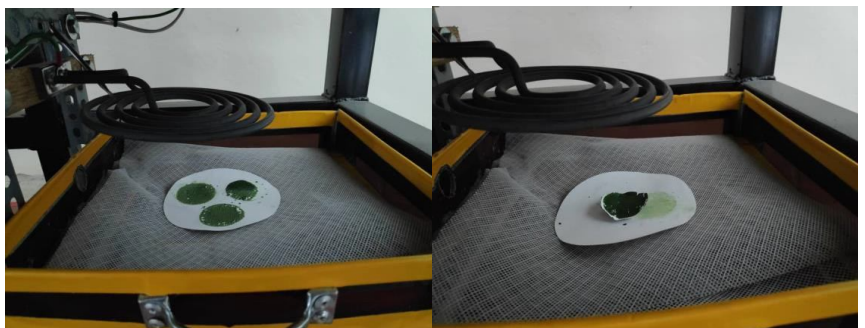

(a)

(b)

Figure 8: Wet microalgae in the drying system (a) Microalgae using filter paper (b) Microalgae using membrane filter

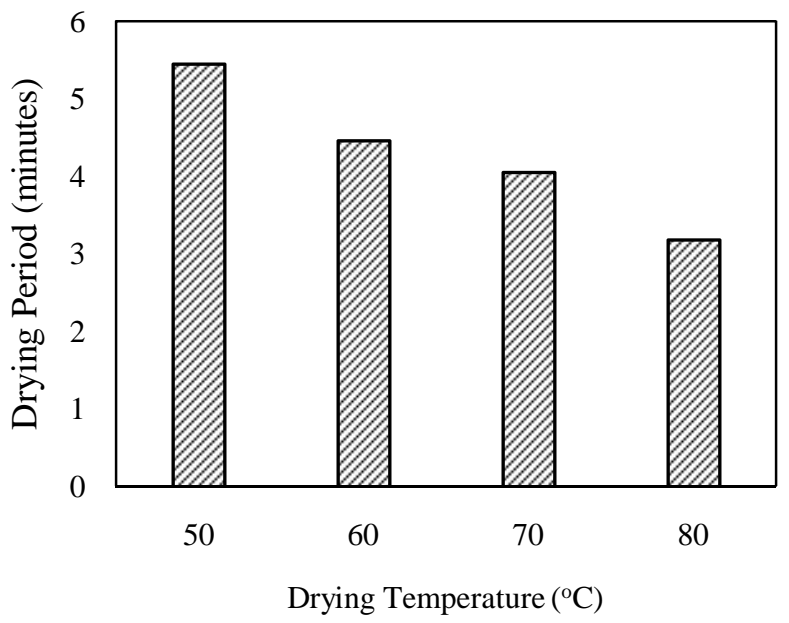

Figure 9:Average drying duration

Figure 9 shows that the drying temperature was inversely proportional to the drying period. When the drying temperature increased, the drying period decreased. This was a result of the heat released from the heater coil at $80^{\circ} \mathrm{C}$, which was greater than the initial pre-set temperature $\left(50^{\circ} \mathrm{C}\right)$ and it shortened the period of the drying process.

\subsection{Comparison between filter paper and membrane filter}

Figure 10 shows the comparison of filter paper based on the recorded weight or the initial weight of the wet microalgae and the weight of dry microalgae. Besides, the filtering period for each medium of filtration, and the drying period were recorded for comparisons. The recorded data was at $60^{\circ} \mathrm{C}$ drying temperature.

Based on Equation 1, the efficiency of the filter paper was $39 \%$ whereas the efficiency of the membrane filters was $53 \%$. Therefore, more microalgae were harvested via the membrane filter as a result of smaller pore sizes in comparison to the filter paper. Additionally, the filtration period for the membrane filter was faster with 5.13 minutes in comparison to 13.31 minutes for the filter paper. Although the pore sizes of filter paper were bigger than the membrane filter, it required more time to filter the microalgae culture. This happened because the microalgae culture clogged up at the pores of the filter paper. When the pores were clogged, despite the large pore sizes, the particles of microalgae could hardly pass through the pores of the filter. Then, the microalgae culture flow became slower and prolonged the filtering period.

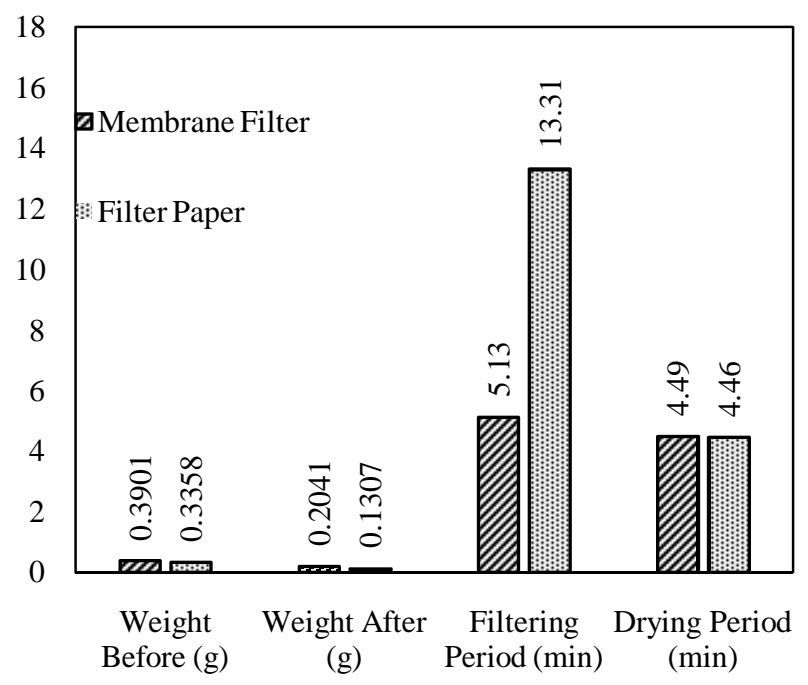

Figure 10:Comparison of filter paper

Both the filtering mediums used the same pre-set temperature for the drying period. The result showed that the drying period was almost the same and did not have any significant difference. In conclusion, the membrane filter was better because it harvested more microalgae than filter paper and therefore, the filtration process was less time-consuming. However, it cost more than filter paper.

\subsection{Dry weight of microalgae}

For this analysis, the filter paper was used to investigate the effect of different drying temperatures. The harvesting efficiency of filter paper was lower compared to the membrane filter. However, the existing microalgae pilot plant filtering system used the filter paper. Hence, it was necessary to study the suitable drying temperature to obtain the optimum harvested microalgae via filter paper.

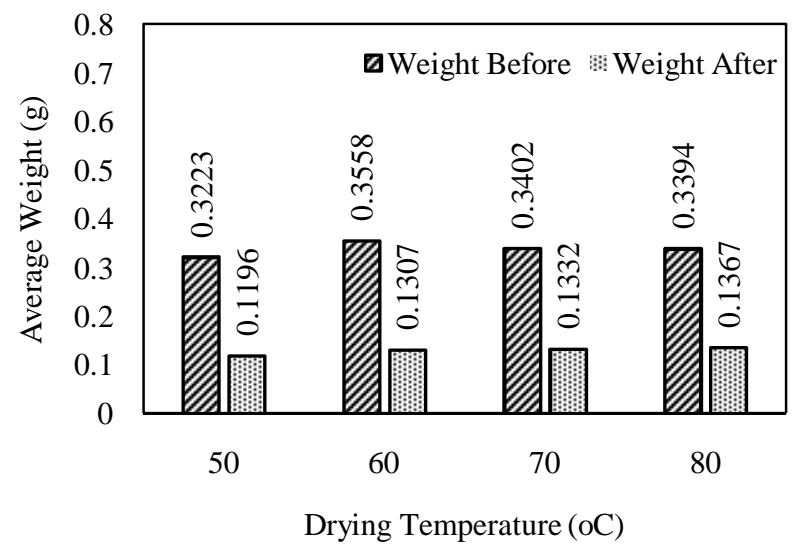

Figure 11: Average weight of microalgae-based on drying temperature 
Figure 11 shows the average weight of microalgae, which was harvested from the microalgae culture (weight after). However, the harvestable dry microalgae did not exhibit many changes for the drying temperature above $60^{\circ} \mathrm{C}$ in comparison to $50^{\circ} \mathrm{C}$.

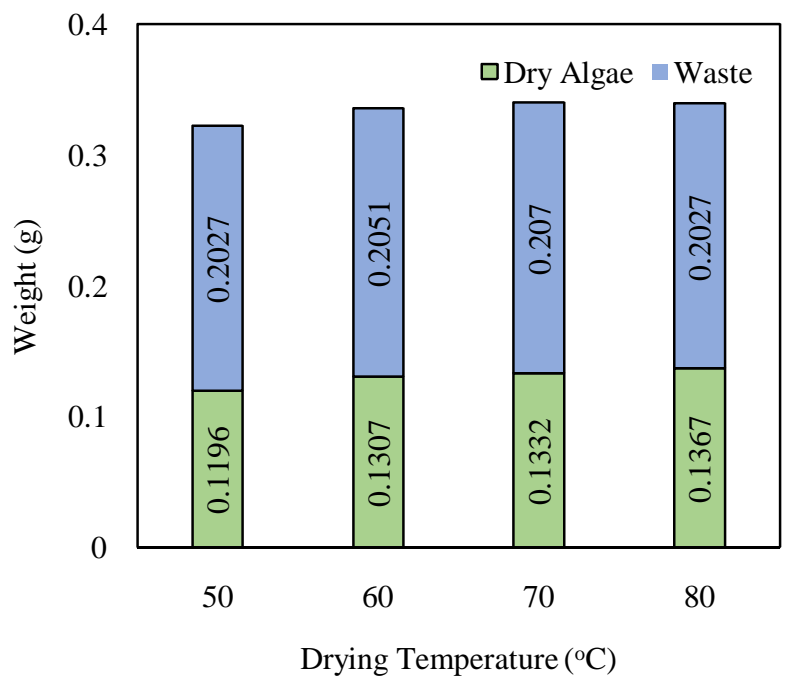

Figure 12:Dry microalgae weight in wet microalgae

Based on Equation 1, about 37\%, $39 \%, 39 \%$, and $40 \%$ of dry microalgae weight was extracted from the microalgae paste for the drying temperature of $50^{\circ} \mathrm{C}, 60^{\circ} \mathrm{C}, 70^{\circ} \mathrm{C}$, and $80^{\circ} \mathrm{C}$ respectively. Figure 12 shows the balance weight, which represented the water contained (waste) in the microalgae paste. Results proved that at a high temperature, high microalgae can be extracted. Therefore, a temperature of $80^{\circ} \mathrm{C}$ harvested about 0.1367 gram of dry microalgae. However, Figure 13 reveals that based on the drying temperature and drying period, the most efficiently harvested dry microalgae was at a drying temperature of $70^{\circ} \mathrm{C}$. The $39 \%$ rate of efficiency and a four-minute drying duration were the standard temperature setting for this microalgae pilot plant.

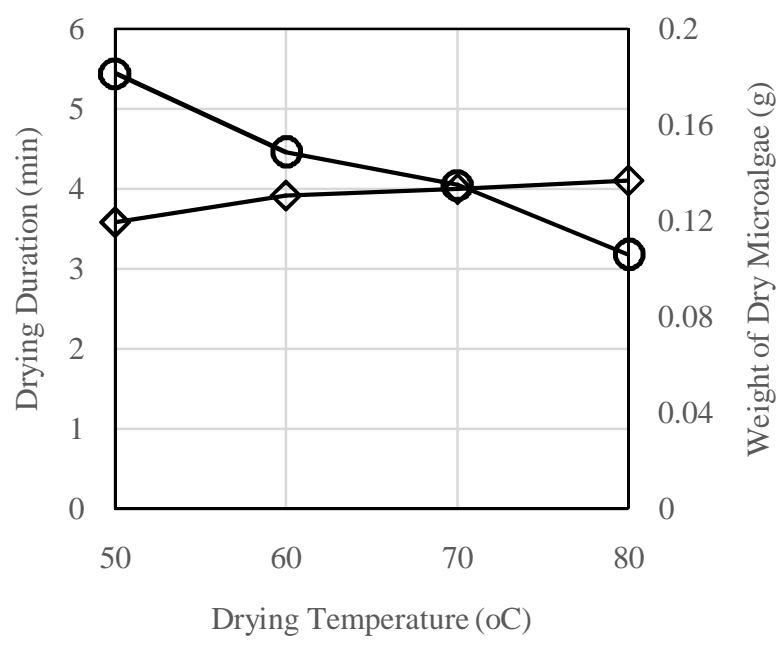

Figure 13:Drying temperature, drying period, and dry weight of microalgae

\section{CONCLUSION}

In conclusion, the membrane filter revealed to be a better choice for the filtration process of the microalgae pilot plant. It harvested about $53 \%$ of microalgae in comparison to filter paper (39\%). The filtration period was also faster compared to the filter paper. However, it is expensive. The current investigation found that at the drying temperature of $70^{\circ} \mathrm{C}$, the existing microalgae pilot plant provided the most efficient outcome via filter paper. Additionally, a vacuum pump should be added to the existing filter system to expedite the filtering process.

\section{ACKNOWLEDGEMENT}

The authors would like to convey their gratitude to Universiti Tun Hussein Onn Malaysia (UTHM) for supporting this research under the Internal Research Grant (TIER 1), Vot No. $\mathrm{H} 255$.

\section{REFERENCES}

1. M. I. A. Jamal. Microalgae Pilot Plant Oil Drying System for Biodiesel Production, Universiti Tun Hussein Onn Malaysia, 2017.

2. P. Gani, N. M. Sunar, H. Matias-Peralta, R. M. S. R.Mohamed, A. A. A. Latiff, and U. K. Parjo. Extraction of hydrocarbons from freshwater green microalgae (Botryococcus sp.) biomass after phycoremediation of domestic wastewater,International Journal of Phytoremediation, 2017.

3. P.Gani, N. M.Sunar, H.Matias-Peralta, A. A. A.Latiff, U. K.Parjo, andA. R. A.Razak.Phycoremediation of wastewaters and potential hydrocarbon from microalgae: A review,Advances in Environmental Biology, 9(20), pp. 1-8, 2015.

4. S. A.Khan, Rashmi, M. Z.Hussain, S.Prasad, and, U. C.Banerjee.Prospects of biodiesel production from microalgae in India,Renewable and Sustainable Energy Reviews, 13(9), pp. 2361-2372, 2009.

5. R. A. I.Abou-Shanab, M. K.Ji, H. C.Kim, K. J.Paeng, andB. H. Jeon.Microalgal species growing on piggery wastewater as a valuable candidate for nutrient removal and biodiesel production,Journal of Environmental Management, 115, pp. 257-264, 2013.

6. T. V.Ramachandra, M.Durga Madhab, S.Shilpi, and N. V. Joshi.Algal biofuel from urban wastewater in India: Scope and challenges, Renewable and Sustainable Energy Reviews, 21, pp. 767-777, 2013.

7. X.Wu, R.Ruan, Z.Du, andY. Liu. Current status and prospects of biodiesel production from microalgae, Energies, 5(12), pp. 2667-2682, 2012.

8. R.Bhave, T. Kuritz, L.Powell, andD. Adcock. Membrane-based energy efficient dewatering of microalgae in biofuels production and recovery of value added co-products, Environmental Science and Technology, 46(10), pp. 5599-5606, 2012.

9. M.Al Hattab, A.Ghaly, and A. Hammouda. Microalgae Harvesting Methods for Industrial Production of Biodiesel: Critical Review and Comparative 
Analysis,Journal of Fundamentals of Rnewable Energy and Applications, 5(2), pp. 1-26, 2015.

10. M.Aziz, T.Oda, and T. Kashiwagi.Integration of energy-efficient drying in microalgae utilization based on enhanced process integration,Energy, 70, pp. 307-316, 2014.

11. J.Kim, G.Yoo, H.Lee, J.Lim, K.Kim, C. W.Kim, M. S.Park, andJ. W.Yang. Methods of downstream processing for the production of biodiesel from microalgae,Biotechnology Advances, $31(6), \quad \mathrm{pp}$. 862-876, 2013.

12. L.Lardon, A.Hélias, B.Sialve, J. P.Steyer, andO. Bernard.Life-cycle assessment of biodiesel production from microalgae,Environmental Science and Technology, 43(17), pp. 6475-7481, 2009.

13. J.Singh, andS. Gu. Commercialization potential of microalgae for biofuels production, Renewable and Sustainable Energy Reviews, 14(9), pp. 2596-2610, 2010.

14. C. L.Chen, J. S.Chang, andD. J. Lee.Dewatering and Drying Methods for Microalgae, Drying Technology, 33(4), pp. 443-454, 2015.

15. T. M.Mata, A. A.Martins, andN. S. Caetano.Microalgae for biodiesel production and other applications: A review, Renewable and Sustainable Energy Reviews, 14, pp. 217-232, 2010.

16. J. J.Milledge, andS. Heaven. A review of the harvesting of micro-algae for biofuel production, Reviews in Environmental Science and Bio/Technology, 12(2), pp. 165-178, 2013.

17. L.Christenson, and R. Sims. Production and harvesting of microalgae for wastewater treatment, biofuels, and bioproducts,Biotechnology Advances, 29(6), pp. 686-702, 2011.

18. E. G.Oliveira, G. S.Rosa, M. A.Moraes, andL. A. A. Pinto. Characterization of thin layer drying of Spirulina platensis utilizing perpendicular air flow,Bioresource Technology, 100(3), pp. 1297-1303, 2009. 